
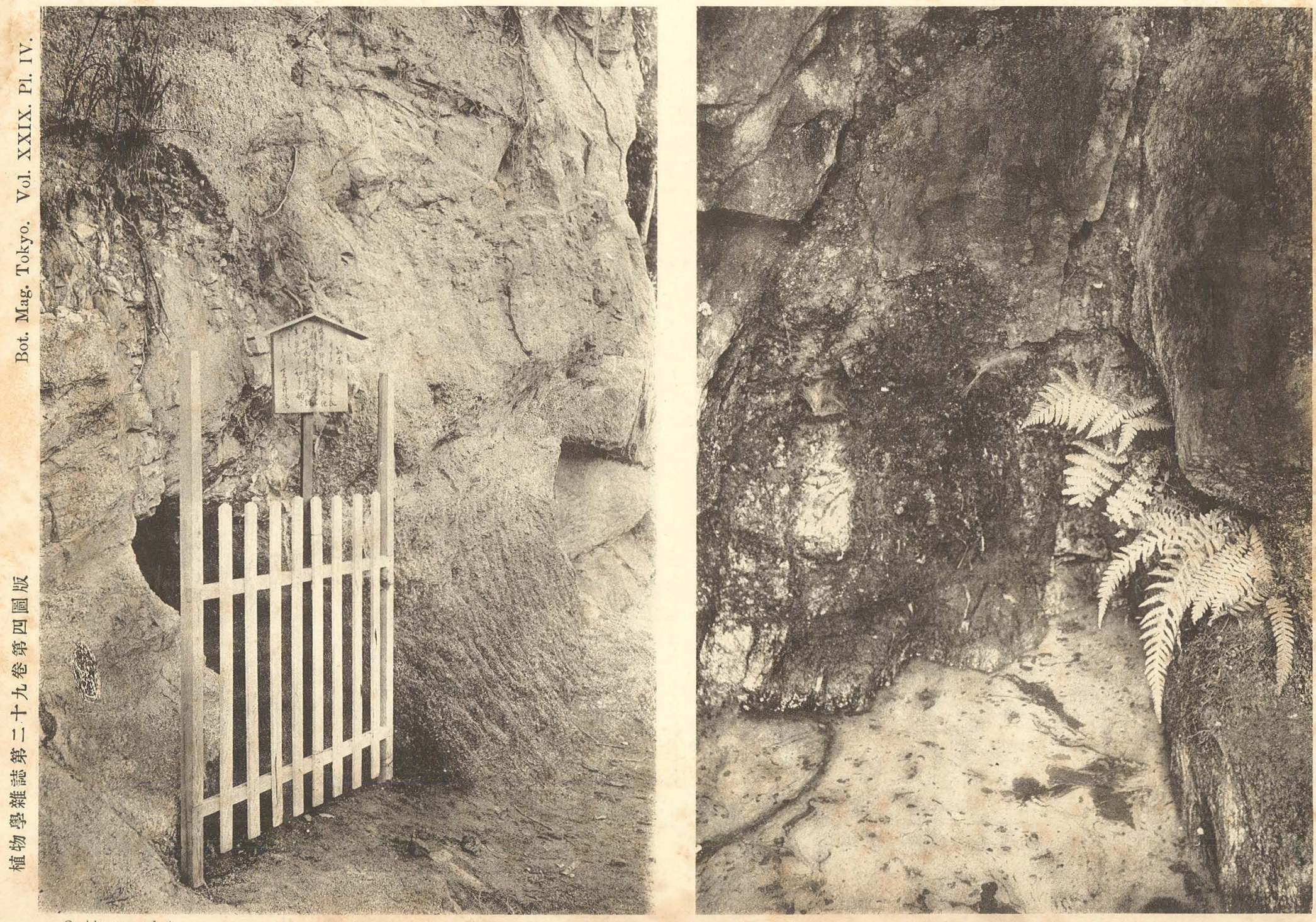


\title{
Ueber das Leuchtwasser und dessen Schutz in Japan.
}

Von

\author{
M. Mi y os hi.
}

Mit I Tafel.

Das Leuchtwasser, welches durch das massenhafte Auftreten von Chromulina Rosanoffii verursacht wird, ist in Europa schon lange bekannt. Ich selber hatte Gelegenheit, auf meiner letzten Reise nach Europa im Jahre 1913 eine solche Stelle im ,, Felsenmeer" der Luisenburg bei Wunsiedel in Deutschland zu besuchen. ${ }^{1)}$ Die Oberfläche eines Brunnenwassers war dicht mit gelblichem Staub bedeckt und zeigte gegen die Sonne einen prachtvollen goldigen Glanz. Nach der persönlichen Mitteilung des Herro Dr. A. Schmidt, dem ich manche wertvolle Winke zur Besichtigung dieser Gegend verdanke, ist das Leuchtwasser neben dem Leuchtmoos, welches auch hier im Felsenmeer vorkommt, als Naturdenkmal geschützt.

Bereits vor meiner Abreise nach Europa bekam ich ats der Provinz Awa, die unweit von Tokyo liegt, die Mitteilung, dass das Wasser eines Brunnens mit goldenem Glanz leuchte. Zugleich erhielt ich auch eine Probe dieses Wassers. Obgleich ich bei der Untersuchung des Wassers intakte Zellen der C. Rosanoffii nicht finden konnte, tauchte mir natülich die Vermutung auf, dass die genannte Erscheinung sicher dem betreffenden Organismus zuzuschreiben sei.

Einige Zeit darauf teilte mir Herr N. TANAKA, der Besitzer der bekannten Higeta-Soja Fabrik in Choshi mit, dass ein Leuchtwasser von grosser Schönheit in der Bentenkutsu-Grotte in Hagiu, Provinz Kadsusa, zu finden sei.

1) Vergl. A. Sснмідт: Führer durch das Fichtelgebirge und den Steinwald. V. Aufl. 1910, p. $30,87$. 
Im Sommer 1914 meldete die Tokyoer Zeitung Jiji-Shimpo das Vorkommen eines Leuchtwassers in der Ungebung von Iida, Provinz Shinano, und ferner, dass es, wie STUd. RER. NAT. S. Tsursur durch Untersuchung herausfand, durch $C$. Rosanoffii verursacht ist. Bald darauf berichtete mir Herr T. Miyakawa, Lehrer der Naturgeschichte an der Mittelschule in Iida, dass das Leuchtwasser in einem Brunnen in Shimo-Toraiwa bei Iida vorkommt. Er sandte mir eine Wasserprobe, welche nach der mikroskopischen Untersuchung nur einige Reste von ChromulinaZellen enthielt; der grosse Teil freilebender Zellen wurde während der Versendung beschädigt und beinahe desorganisiert. Trotz dieses unvollständigen Materials blieb kein $Z_{\text {weifel, dass }}$ das Leuchten des Brunnenwassers durch C. Rosanoffii zu Stande kommt.

Um aber die Leuchterscheinung an Ort und Stelle genauer zu untersuchen, reiste mein Assistent DR. S. Hibino nach der oben genannten Örtlichkeit und bestätigte vollkommen die Befunde von Tsutsur und von mir. Die Resultate seiner Untersuchung wurden bereits in der vorigen Nummer dieser Zeitschrift in japanischer Sprache publiziert.

Der Brunnen von Shimo-Toraiwa, wo das Leuchtwasser vorkommt, befindet sich, wie in dem oben genannten Artikel mitgeteilt ist, an der Südseite eines kleinen Hügels. Das Wasser ist seicht und klar, und seine Oberfläche ist von der Sonne belichtet.

Der goldige Glanz der Wasseroberfläche tritt nur im diffusen Lichte deutlich zu Tage, bei starker Besonnung dagegen geht er in einen weisslich-gelben Ton über,-eine Farbenänderung, die durch Bewegung der Chromatophoren infolge der gesteigerten Lichtintensität zu Stande kommt.

Im letzten Herbst machte Marquis Y. Tokugawa mit mir und anderen eine Exkursion nach Hagiu, um das dortige Leuchtwasser $z u$ besichtigen. Am Abhange eines der Meereskiuste entlang liegenden Hügels sieht man eine Grotte, die ca. $2 \mathrm{~m}$ breit, $8 \mathrm{~m}$ tief und $4 \mathrm{~m}$ hoch ist. Das Bett der Grotte bildet ein Brunnen, welcher mit trübem Wasser gefüllt ist. Wider Erwarten leuchtete das Wasser in der Zeit leider nicht, wahrscheinlich infolge von Untersinken oder Zerstreuung der am Wasserspiegel 
liegenden Zellen aus unbekannter Ursache. Ich entnahm mehrere Wasserproben und konnte nur mit Schwierigkeiten einige Chromulinazellen unter dem Mikroskope finden. Es war schon Spätherbst, die Zeit war nicht mehr günstig, um das Leuchtphänomen zu beobachten. Wie man uns erzählte, ist das prachtvolle Leuchten nur von Mitte Frühling bis zum Spätsommer zu sehen.

Ausser den oben genannten zwei Stellen kommt nach HERrN TsuTsur ein ganz gleichartiges Leucht wasser in einer kleinen Grotte im Grundstück der VII. Höheren Schule zu Kagoshima vor.

Es ist zu erwarten, dass C. Rosanoffii und ev. das Leuchtwasser noch in manchen anderen Gegenden gefunden werden. Wahrscheinlich ist dieser Organismus in Japan weit verbreitet, nur findet seine massenhafte Entwicklung in der Natur ziemlich selten statt.

Es ist nur einige Jahre her, dass das Leuchtmoos ${ }^{1)}$ in der Provinz Shinano bekannt geworden ist, und nun folgt die Entdeckung des Leuchtwassers dort und in anderen Provinzen. So muss es mit Freude begrüsst werden, dass in Japan immer wieder neue botanische Schätze entdeckt werden. Vom Standpunkte der Naturdenkmalpflege bedürfen das Leuchtwasser und ebenso das Leuchtmoos eines geigneten Schutzes. Wie wir erfahren haben, liessen die Besitzer der Brunnen an den oben erwähnten Stellen, wo das Leuchtwasser vorkommt, den Eingang bereits mit einem Zaun sperren, um irgend eine Ausnützung des Wassers zu verhuiten. Somit ist die Vernichtung des interessanten Naturobjekts nicht mehr zu befürchten.

\section{Tafelerklärung.}

Fig. 1. Aussenansicht der Schutzstelle des Leuchtwassers in Shimo-Toraiwa bei Iida, Shinano. Der Eingang des Brunnens ist eingezäunt. (HrbIvo phot. am 20. Sept. 1914.)

Fig. 2. Innenansicht des Brunnens mit Leuchtwasser. (HıBıno phot.)

1) Vergl. M. MıYoshr: Ueber die Kultur der Schistostega osmundacea, Schimp. Bot. Mag. Tokyo, Vol. XXVI, p. 304, 1912. 